\title{
Single-side hydrolysis of hollow fiber polyacrylonitrile membrane by an interfacial hydrolysis of a solvent-impregnated membrane
}

\author{
Guojun Zhang a,*, Xue Song ${ }^{\mathrm{a}}$, Jie Li ${ }^{\mathrm{a}}$, Shulan Ji ${ }^{\mathrm{a}, *}$, Zhongzhou Liu ${ }^{\mathrm{b}}$ \\ a Center for Membrane Technology, College of Environmental and Energy Engineering, Beijing University of Technology, Beijing 100124, PR China \\ ${ }^{\mathrm{b}}$ Research Center for Eco-Environmental Sciences, Chinese Academy of Sciences, Beijing 100085, PR China
}

\section{A R T I C L E I N F O}

\section{Article history:}

Received 5 May 2009

Received in revised form

29 September 2009

Accepted 27 December 2009

Available online 7 January 2010

\section{Keywords:}

Interfacial hydrolysis

Cyclohexane/water phase interface

Polyacrylonitrile

Hollow fiber

Polyelectrolyte multilayer membranes

Pervaporation

\begin{abstract}
A B S T R A C T
In this paper, a new method was proposed to improve the mechanical strength and flux of polyacrylonitrile (PAN)-based membrane by a single-side hydrolysis of hollow fiber PAN substrate membrane. A non-water miscible solvent of cyclohexane was firstly incorporated into membrane pores to form cyclohexane-impregnated hollow fiber PAN membrane by stepwise solvent replacement method. Alkaline aqueous solution was then fed into lumen side to introduce interfacial hydrolysis reaction on the inner surface of hollow fiber by using the cyclohexane/water phase interface. After the reaction, the cyclohexane incorporated was displaced by water to remain the pore pathway. The ATR-FTIR and EDX analyses confirmed that the alkaline hydrolysis did not occur in the membrane pores. SEM and AFM were also conducted to further understand the microtopographical changes on membrane surfaces. During the assembly of PAN-based polyelectrolyte pervaporation composite membranes, both flux and mechanical strength was highly improved by using single-side hydrolysis of PAN substrate membrane while the selectivity was still kept at a relatively high level.
\end{abstract}

(C) 2010 Elsevier B.V. All rights reserved.

\section{Introduction}

Polyacrylonitrile (PAN) possesses excellent properties, such as good thermal and mechanical stability, tolerance to most solvents and commercial availability [1,2]. Therefore, PAN has been successfully applied as one of the fascinating membrane materials. In recent years, one of the most important applications is that the porous PAN UF membranes were used as the supports for nanofiltration and pervaporation composite membranes [3-14]. This is because PAN membrane surface is relatively active and in turn the property is much easier to be modified. The modifications of PAN UF membranes usually include plasma treatment [3], plasma-initiated graft polymerization [4-6], photo-induced grafting [7] and hydrolysis [8-14]. Among these methods, alkaline hydrolysis is one of the most important and most frequently used methods for PAN-based membranes, due to the convenience and favorableness for further modification. The hydrolysis with alkaline solution is based on the conversion of $-\mathrm{CN}$ groups on the PAN membrane surface firstly into $-\mathrm{CONH}_{2}$, then into - $\mathrm{COO}^{-}$groups $[1,7,9,10]$. A number of studies have reported the PAN-based composite membranes. For examples, Wang et al. [8] prepared asymmetric PAN nanofiltration membranes with controlled highly dense pore surface functional groups

\footnotetext{
* Corresponding authors. Tel.: +8610 67392961; fax: +861067391983.

E-mail addresses: zhanggj@bjut.edu.cn (G. Zhang), jshl@bjut.edu.cn (S. Ji).
}

by hydrolysis of the nitrile groups with $\mathrm{NaOH}$. In our previous studies [10-12], the polyelectrolyte multilayer membranes (PEMMs) have already been successfully assembled on a hydrolyzed PAN UF membrane. It was noted that the hydrolysis degree has a great influence on the subsequent modifications $[10,14]$. In addition to the above application, the hydrolysis could modulate its antifouling and the rejection properties. For instance, Qiao et al. [15] recently used the PAN UF membrane with hydrophilic modification to purify Chinese herbs. It was found that the content of danshensu and protocatechuic aldehyde in the permeate is different when PAN membranes with different hydrophilicities are employed for filtration. More recently, Lohokare et al. [16] have reported that the hydrolysis of PAN-based UF membrane surface by $\mathrm{NaOH}$ leading to the formation of carboxylate groups and reduction in initial pore size rendered As-V rejection capability by Donnan exclusion principle. Obviously, modulating the structure of PAN membrane with alkaline hydrolysis is significant for practical applications.

However, it is well known that the hydrolysis of PAN membrane would lead to the reduction of mechanical strength. Therefore, to ensure a suitable mechanical strength for the subsequent modification or separation process, excess hydrolysis is usually not expected. Additionally, it has been reported that the hydrolysis of PAN UF membrane would change the membrane pore size and in turn affect the flux of subsequent modified membrane [10,14]. In the past studies, to accomplish the hydrolysis, the PAN mem- 


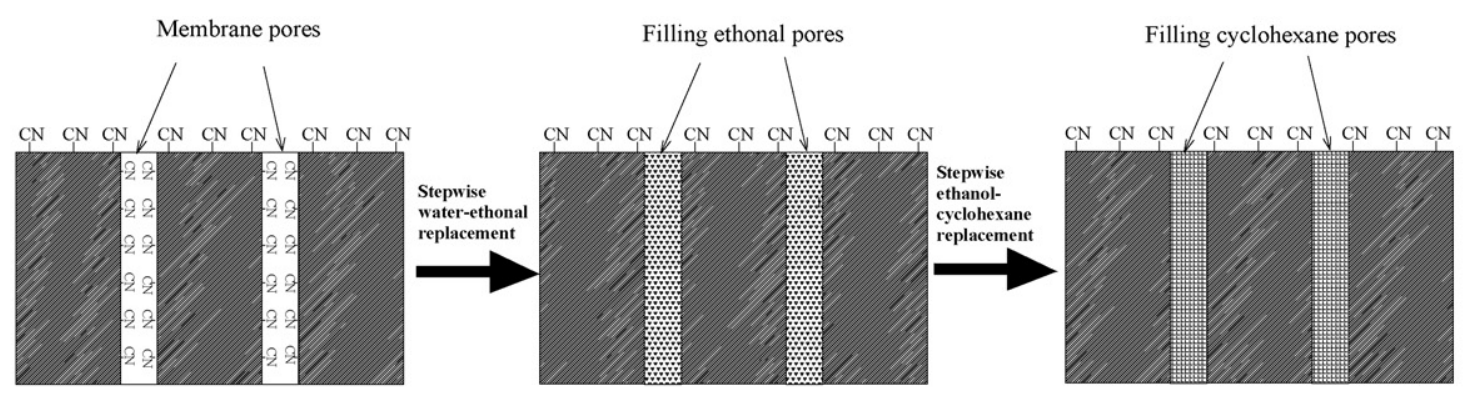

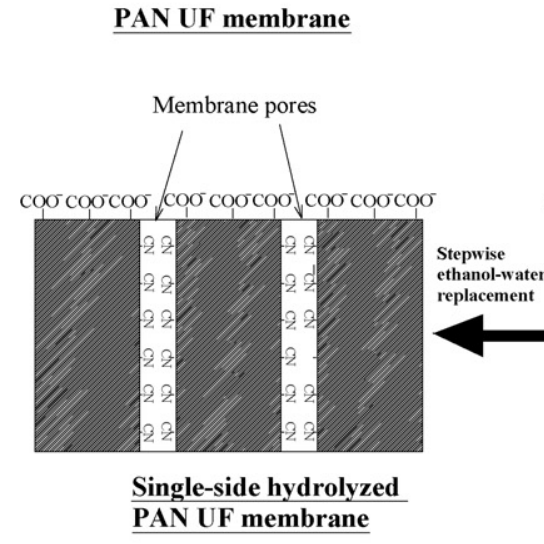

Ethanol-impregnated PAN UF membrane

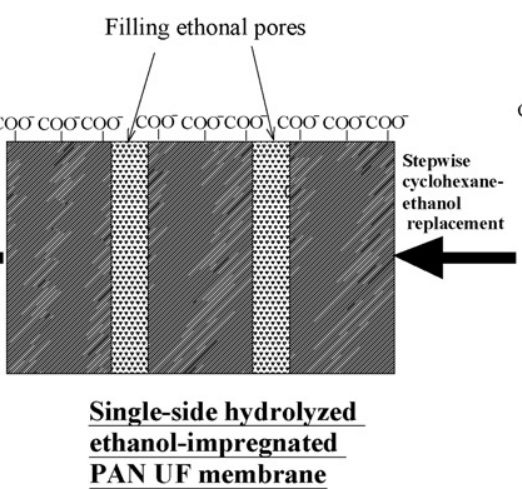

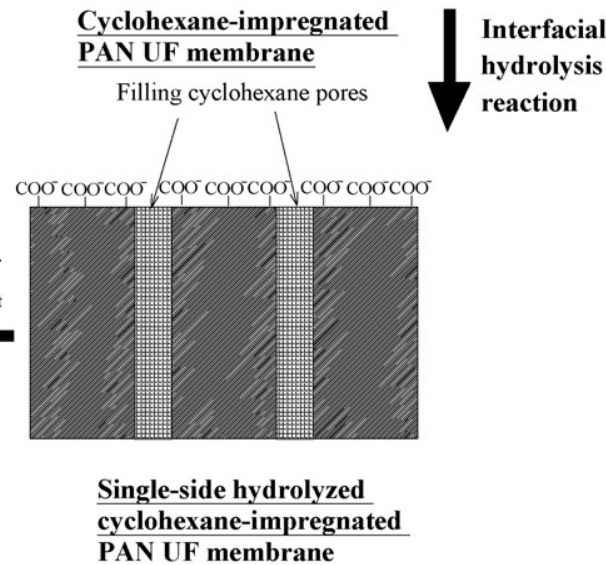

Fig. 1. Principles of interfacial hydrolysis of a solvent-impregnated membrane.

branes were usually entirely immersed into the alkaline solution [8-14]. Even if the PAN membrane was initially contacted alkaline solution with single-side surface, it was observed that a few $\mathrm{NaOH}$ solutions could always permeate through the membranes. Therefore, the hydrolysis would take place inside of membrane pores and on both sides of surface. As the hydrolysis is mainly to change the surface properties of the substrate membrane, preferably only the surface of the substrate should be hydrolyzed [14]. In order to improve the mechanical strength and the flux of PANbased composite membrane, it is expected that single-side surface hydrolysis rather than entire hydrolysis is necessary. However, it is a technical problem to achieve hydrolysis only on single-side surface. In this study, a new interfacial hydrolysis method was proposed to implement the single-side surface hydrolysis of PAN UF membrane. A schematic diagram, which simply describes the principles of interfacial hydrolysis of PAN UF membrane, is shown in Fig. 1. As shown in Fig. 1, a non-water miscible solvent of cyclohexane was firstly incorporated into membrane pores to form cyclohexane-impregnated hollow fiber PAN membrane by stepwise solvent replacement method. After that, interfacial hydrolysis reaction would take place on cyclohexane/water phase interface by introducing alkaline solution into lumen side of hollow fibers. The single-side hydrolysis was confirmed by ATR-FTIR spectra and EDX measurements. SEM and AFM were also conducted to further understand the microtopographical changes on membrane surfaces. The permeability and retention capacity obtained from single-side and entire hydrolyses were compared. The change of the tensile strengths and elastic modulus was also determined during the hydrolysis process according to the two modifications. Additionally, the pervaporation composite membrane was prepared by alternatively depositing polyacrylic acid (PAA) and polyethyleneimine (PEI) on a hydrolyzed hollow fiber PAN membrane under a negative pressure condition. The improvements of pervaporation flux and mechanical strength were therefore investigated.

\section{Experimental}

Sodium hydroxide, ethanol and cyclohexane were of analytical grade. A series of poly(ethylene glycol)s (PEGs) having the molecular weight of $6000,10,000$ and 20,000 were supplied by Beijing Chemical Factory. The polyacrylic acid (PAA) powder having average molecular weight of 4,000,000 and branched poly(ethyleneimine) (PEI) with the molecular weight of 60,000 were obtained from Aldrich and ACROS, respectively.

The hollow fiber membranes were produced by the phase inversion method from PAN polymer in our workshop [17]. The inner diameter of each hollow fiber was $1.1 \mathrm{~mm}$. The wet hollow fiber PAN UF membranes were orderly immersed into $25 \mathrm{wt} \%$, $50 \mathrm{wt} \%$ and $75 \mathrm{wt} \%$ ethanol-water mixtures and then ethanol solvent. The immersion time in each ethanol-water mixture was $2 \mathrm{~h}$. In this way, the ethanol firstly incorporated into the membrane pores by replacing the water remained in the pores. The ethanolimpregnated hollow fiber membranes were followed by $2 \mathrm{~h}$ of immersion into $25 \mathrm{wt} \%, 50 \mathrm{wt} \%$ and $75 \mathrm{wt} \%$ cyclohexane-ethanol mixtures and cyclohexane solvent, respectively. Then, $2 \mathrm{~N} \mathrm{NaOH}$ aqueous solution at the temperature of $60^{\circ} \mathrm{C}$ was fed into lumen side to introduce interfacial hydrolysis reaction on the inner surface of hollow fibers. After the hydrolysis reaction for $15 \mathrm{~min}$, the membranes were rinsed with de-ionized water until the $\mathrm{pH}$ values of the rinsed water reached about 7.0. Reversely, the single-side hydrolyzed PAN membranes were orderly immersed into $75 \mathrm{wt} \%$, $50 \mathrm{wt} \%, 25 \mathrm{wt} \%$ cyclohexane-ethanol mixtures and ethanol solvent. Subsequently, the ethanol-impregnated membranes were replaced by $75 \mathrm{wt} \%, 50 \mathrm{wt} \%$ and $25 \mathrm{wt} \%$ ethanol-water mixtures, and then pure water. Each immersion time still remains $2 \mathrm{~h}$. By using this stepwise solvent replacement method, cyclohexane incorporated was finally displaced by water. As a comparison, the entire hydrolysis was also conducted by directly immersing hollow fiber PAN membranes into $2 \mathrm{~N} \mathrm{NaOH}$ aqueous solution for $15 \mathrm{~min}$ at the temperature of $60^{\circ} \mathrm{C}$. To characterize the differences of membrane 
Table 1

EDX analytical results of sodium element in the surface and pores of hydrolyzed hollow fiber PAN membrane.

\begin{tabular}{|c|c|c|c|c|c|}
\hline \multirow[t]{2}{*}{ Membrane } & \multirow[t]{2}{*}{$\begin{array}{l}\text { Sodium content on the } \\
\text { outer surface (wt\%) }\end{array}$} & \multirow[t]{2}{*}{$\begin{array}{l}\text { Sodium content on the } \\
\text { inner surface ( } w t \%)\end{array}$} & \multicolumn{3}{|c|}{$\begin{array}{l}\text { Sodium content on the cross-section of membrane } \\
\text { pore (wt } \% \text { ) }\end{array}$} \\
\hline & & & Near to inner surface & Middle of cross-section & Near to outer surface \\
\hline Single-side hydrolyzed hollow fiber & 0 & 0.43 & 0 & 0 & 0 \\
\hline Entirely hydrolyzed hollow fiber & 1.45 & 1.99 & 1.83 & 1.04 & 1.36 \\
\hline
\end{tabular}

Hydrolysis conditions for hollow fiber PAN membrane: $2 \mathrm{~N} \mathrm{NaOH}$, hydrolysis temperature: $60{ }^{\circ} \mathrm{C}$, hydrolysis time: 15 min.

performance using the two hydrolysis methods, the pure water fluxes before and after hydrolysis were determined. Meanwhile, the retention ratios of PEG solutions with three molecular weights were compared by calculating from the total organic carbon (TOC) values before and after ultrafiltration. The initial TOC values were controlled at approximately $250 \mathrm{mg} / \mathrm{l}$ for each molecular weight PEG solution.

Based on the single-side hydrolyzed PAN substrate membranes, the PEMMs were also prepared by using a laboratory fabricated cross-flow filtration cell $[12,13]$. The PEI and PAA solutions were alternatively provided into the lumen side of hydrolyzed hollow fiber and then recycled by using two peristaltic pumps and through separate tubings. On the shell side, a vacuum pump was used to form a negative pressure. The PEMMs were assembled by alternatively filtrating PEI and PAA for $30 \mathrm{~min}$. The assembly steps were orderly carried out as previously reported [12,13]. Upon the formation of PEMMs, they were stored for pervaporation experiments. The hollow fiber module for pervaporation test consisted of two fibers with effective lengths of $10 \mathrm{~cm}$ and effective area of $69.1 \mathrm{~cm}^{2}$. The hollow fiber modules were mounted onto a laboratory fabricated pervaporation system with lumen side as the feed side and shell side as the permeate side. Three modules with same fabrication and modification conditions were examined for each pervaporation condition. The permeate vapor was trapped with liquid nitrogen. The experiments were carried out at a down-stream pressure of $100 \mathrm{~Pa}$ by a vacuum pump. Fluxes were determined by measuring the weight of liquid collected in the cold traps during a certain time under steady-state conditions. The composition of the collected permeate was determined by gas chromatography (GC-14C, SHIMADZU by gas chromatography (GC14C, SHIMADZU)) equipped with a TCD detector and a Porapak Q capillary column ( $2 \mathrm{~m} \times 3 \mathrm{~mm}$ i.d.). Hydrogen gas was used as carrier gas. The injection volume was $2 \mu$ l. The injection temperature and column temperature were $130^{\circ} \mathrm{C}$ and $120^{\circ} \mathrm{C}$, respectively. The separation factor was calculated from the quotient of the weight ratio of water and alcohol in the permeate, $Y_{\mathrm{HOH}} / Y_{\mathrm{ROH}}$, and in the feed, $X_{\mathrm{HOH}} / X_{\mathrm{ROH}}$ :

$\alpha=\frac{Y_{\mathrm{HOH}} / Y_{\mathrm{ROH}}}{X_{\mathrm{HOH}} / X_{\mathrm{ROH}}}$

A TOC analyzer (TOC-VCPH, SHIMADZU) was used to determine the TOC values of PEG solutions before and after ultrafiltration. The tensile strengths and elastic modulus at the breaking point were measured using an Instron 4302 universal tensile testing machine under ambient conditions for at least three samples and the average value was recorded. Attenuated total reflectance FTIR spectra were obtained using a Vertex-70 spectrophotometer (Bruker, Germany). A scanning electron microscope (SEM) with a Hitachi 4700 energy dispersive X-ray (EDX) unit (Hitachi, Japan) was used to determine the sodium element of membrane surfaces and membrane pore after hydrolysis. Surface topography was also performed in tapping mode by an atomic force microscopy (AFM) (Pico Scan ${ }^{\mathrm{TM}} 2500$, USA).

\section{Results and discussion}

The ATR-FTIR spectra of PAN membrane after entire and singleside hydrolysis are shown in Fig. 2. For the inner surface (Fig. 2(a)), the band at around $1562 \mathrm{~cm}^{-1}$ in the spectra of hydrolyzed PAN membrane provided strong evidence that carboxyl groups occurred primarily via hydrolysis of alkaline solutions in both hydrolysis reactions. It was clearly observed that the peak at $1562 \mathrm{~cm}^{-1}$ with the entire hydrolysis were relatively stronger than those with single-side hydrolysis. However, for the outer surface, it was noted from Fig. 2(b) that the bands of carboxyl groups did not appear at all in the case of single-side hydrolysis. As a comparison, the band at $1579 \mathrm{~cm}^{-1}$ attributed to carboxyl functionality was very
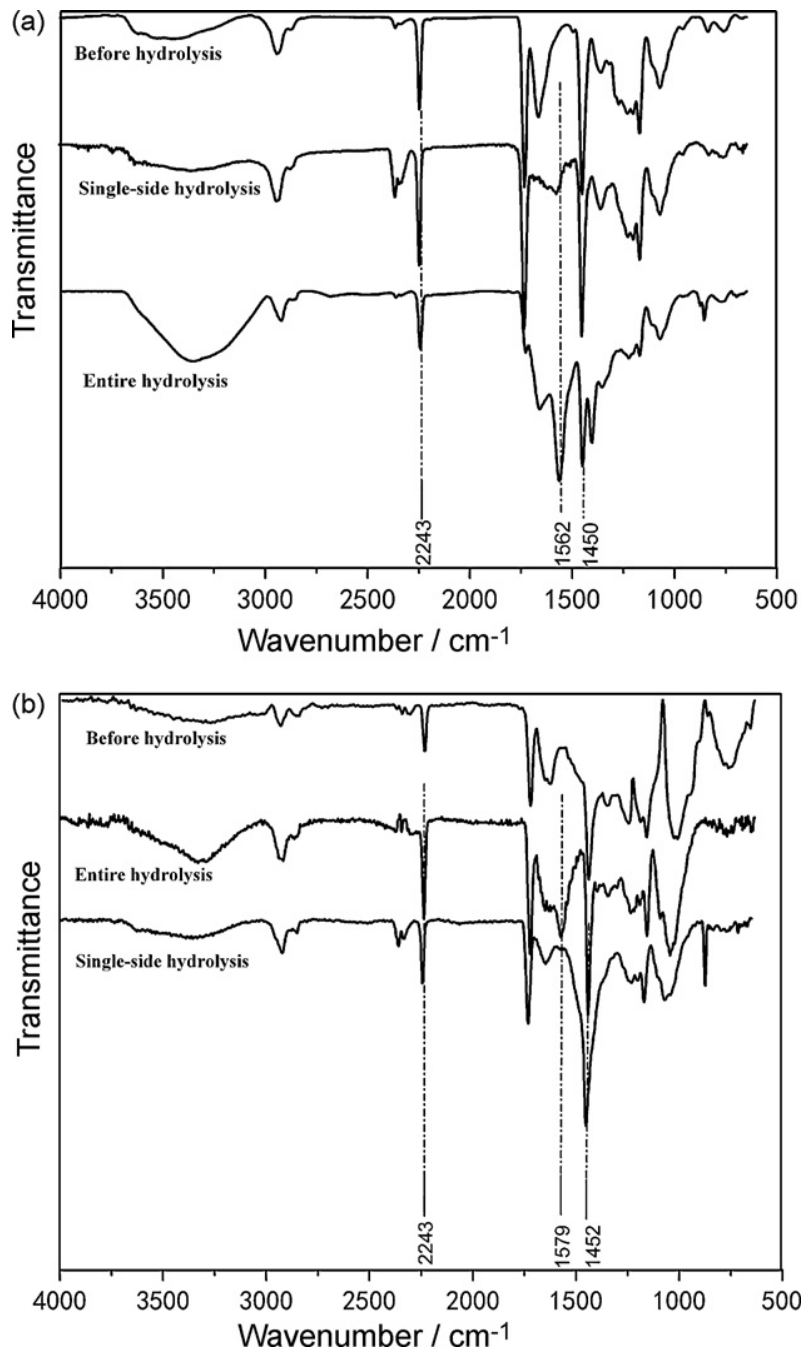

Fig. 2. IR spectra of inner and outer surfaces of PAN membrane with entire and surface hydrolysis. (a) Inner surface. (b) Outer surface. (Hydrolysis conditions for hollow fiber PAN membrane: $2 \mathrm{~N} \mathrm{NaOH}$, hydrolysis temperature: $60^{\circ} \mathrm{C}$, hydrolysis time: $15 \mathrm{~min}$.) 
(a)

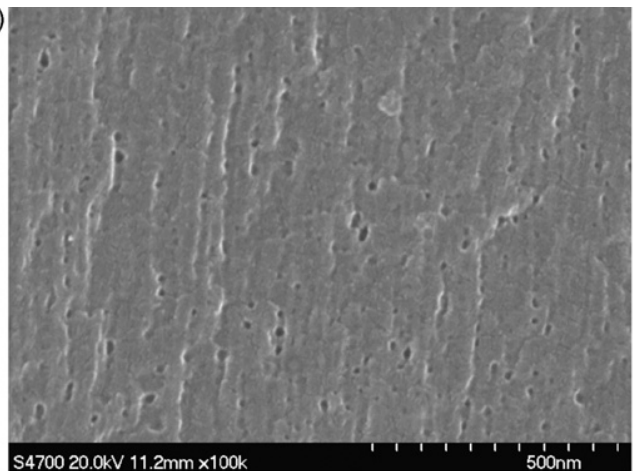

(b)

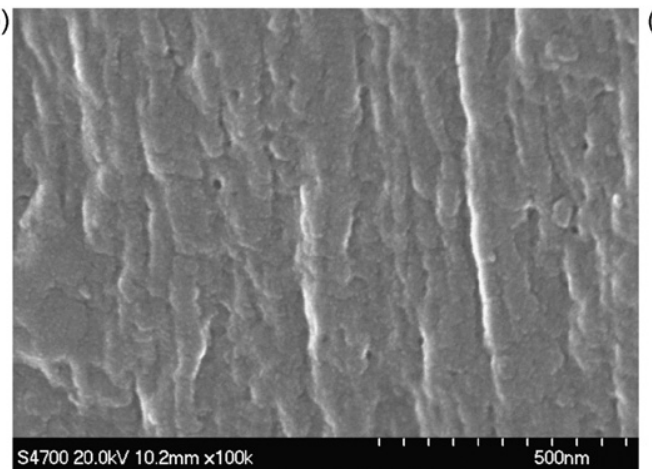

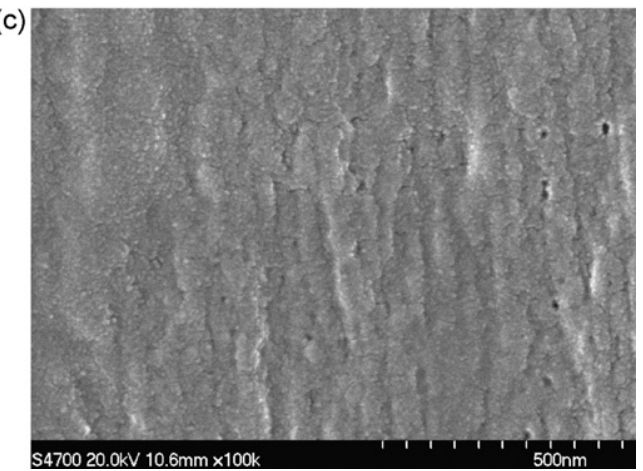

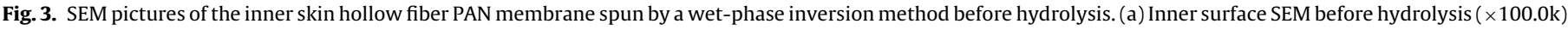

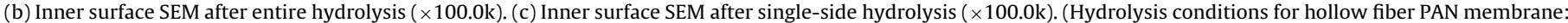
$2 \mathrm{~N} \mathrm{NaOH}$, hydrolysis temperature: $60^{\circ} \mathrm{C}$, hydrolysis time: $15 \mathrm{~min}$ )

strong in entire hydrolysis case. Furthermore, the shoulders at around $2243 \mathrm{~cm}^{-1}$ and $1452 \mathrm{~cm}^{-1}$, which were due to the $-\mathrm{CN}$ group, obtained from single-side hydrolysis were much stronger than those obtained from entire hydrolysis. Therefore, it was concluded that the hydrolysis did not occur at the outer surface for the single-side hydrolysis. Additionally, since the carboxyl functionality would remain in the form of $-\mathrm{COO}^{-} \mathrm{Na}^{+}$, EDX was also used to analyze the sodium content in the membrane pore for both cases. It was noted from Table 1 that the sodium elements still remains in the membrane pores in the entire hydrolysis case, which clearly suggested that the carboxyl functionality formed in the membrane pores. As a comparison, the sodium element was only detectable in the membrane surface in single-side hydrolysis case. The sodium elements were nondetectable from three random places along the cross-sectional pores. This clearly proved that the carboxyl functionality was not formed in membrane pores and the alkaline hydrolysis only occurred on the inner surface. This is because that the hydrolysis reaction only took place on cyclohexane/water phase interface. The cyclohexane incorporated protected membrane pores from hydrolyzing.

The microtopographical changes on membrane surfaces were further compared. The SEM and AFM pictures are presented in Figs. 3 and 4, respectively. It was observed from Fig. 3 that the membrane became more compact after alkaline hydrolysis. Comparing Fig. 3(b) with (c), the membrane surface obtained from entirely hydrolyzed PAN looked much denser than that from the

Table 2

Comparisons of hydrolyzed PAN and PAN-based composite membrane performance.

\begin{tabular}{|c|c|c|c|c|c|c|c|c|}
\hline \multirow[t]{2}{*}{ Membrane } & \multirow{2}{*}{$\begin{array}{l}\text { Pure water flux } \\
\text { of UF membrane } \\
\left(1 / \mathrm{m}^{2} \mathrm{~h}\right)\end{array}$} & \multicolumn{3}{|c|}{ Retention ratio (\%) } & \multicolumn{2}{|c|}{$\begin{array}{l}\text { Pervaporation performance of } \\
\text { PAN-based composite membrane }\end{array}$} & \multirow[t]{2}{*}{$\begin{array}{l}\text { Tensile strength, } \\
\sigma_{\mathrm{t}}(\mathrm{MPa})\end{array}$} & \multirow[t]{2}{*}{$\begin{array}{l}\text { Elastic modulus, } \\
E(\mathrm{MPa})\end{array}$} \\
\hline & & PEG-20000 & PEG-10000 & PEG-6000 & $\begin{array}{l}\text { Water content } \\
\text { in permeate }(\%)\end{array}$ & $\begin{array}{l}\text { Pervaporation } \\
\text { flux }\left(\mathrm{g} / \mathrm{m}^{2} \mathrm{~h}\right)\end{array}$ & & \\
\hline $\begin{array}{l}\text { PAN UF membrane } \\
\text { before hydrolysis }\end{array}$ & 160 & 85.78 & 50.59 & 16.85 & - & - & 2.70 & 89.4 \\
\hline $\begin{array}{l}\text { PAN UF membrane } \\
\text { after entire hydrolysis }\end{array}$ & 82 & 92.23 & 83.99 & 46.75 & - & - & 2.36 & 39.6 \\
\hline $\begin{array}{l}\text { PAN UF membrane } \\
\text { after single-side } \\
\text { hydrolysis }\end{array}$ & 112 & 87.23 & 59.81 & 20.46 & - & - & 2.68 & 79.5 \\
\hline $\begin{array}{l}\text { PEMMs based on } \\
\text { entirely hydrolyzed } \\
\text { hollow fiber }\end{array}$ & - & - & - & - & 97.5 & 135.6 & 2.84 & 94.9 \\
\hline $\begin{array}{l}\text { PEMMs based on } \\
\text { single-side hydrolyzed } \\
\text { hollow fiber }\end{array}$ & - & - & - & - & 97.6 & 285.8 & 2.97 & 98.7 \\
\hline
\end{tabular}

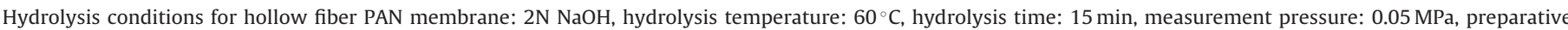

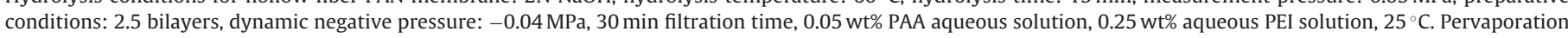
conditions: feed solution $95 \mathrm{wt} \%$ ethanol-water, feed temperature $50^{\circ} \mathrm{C}$, down-stream pressure $100 \mathrm{~Pa}$. 
(a)

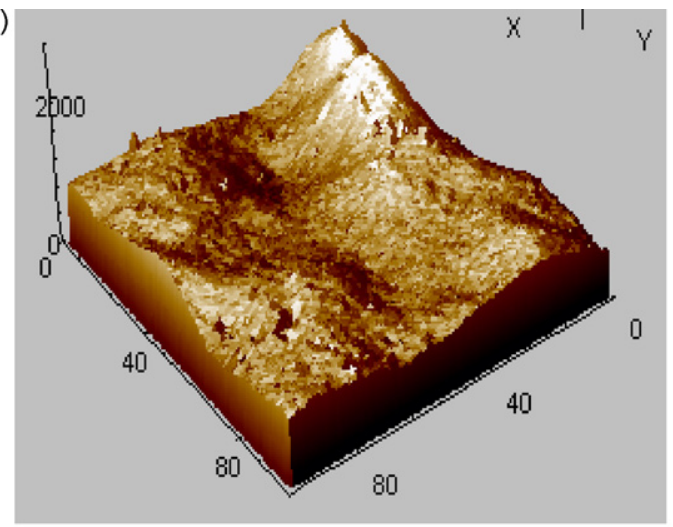

(b)

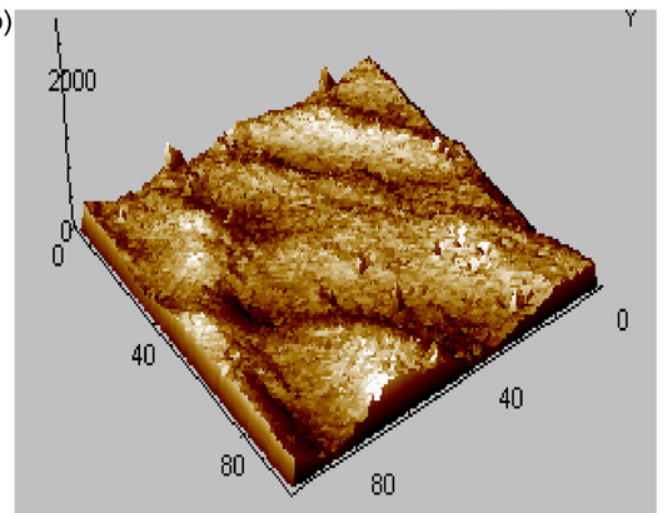

(c)

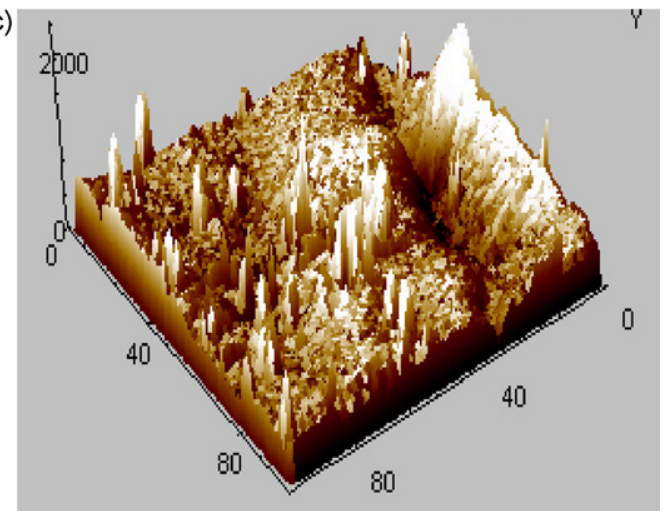

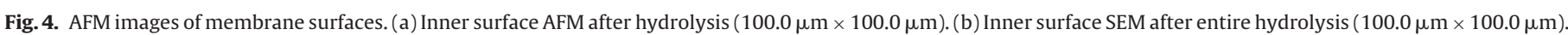

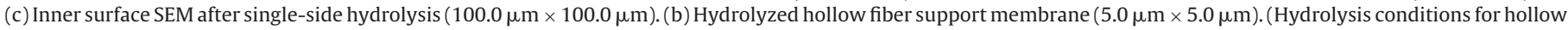
fiber PAN membrane: $2 \mathrm{~N} \mathrm{NaOH}$, hydrolysis temperature: $60^{\circ} \mathrm{C}$, hydrolysis time: $15 \mathrm{~min}$.)

single-side hydrolyzed membrane. The AFM pictures, as shown in Fig. 4, show the top surfaces were also different in two hydrolysis cases. The values of mean roughness $(\mathrm{Ra})$ was obtained based on $100.0 \mu \mathrm{m} \times 100.0 \mu \mathrm{m}$ scan area. The Ra of the PAN membranes decreased from $1227.5 \mathrm{~nm}$ to $344.9 \mathrm{~nm}$ after entirely hydrolyzing. As a comparison, the Ra obtained from single-side hydrolyzed membrane was $717.6 \mathrm{~nm}$. This is because single-side hydrolyzed PAN only create carboxyl group on membrane surface while $-\mathrm{CN}$ group still remains in membrane pores. In contrast, carboxyl groups existed both in membrane surface and in pores after entire hydrolysis. It is well known that the carboxyl group is easily swollen when expose to aqueous medium. The swollen macromolecules made the membrane surface denser and smoother [1]. Therefore, the relatively smaller quantity of carboxyl groups would benefit for the formation of looser and rougher surface in single-side hydrolysis case.

Furthermore, the flux and retention capacity after single-side and entire hydrolysis were compared. The results are summarized in Table 2. As shown in Table 2, the retention ratios of the
PEGs having three molecular weights obtained from single-side hydrolyzed PAN membrane were relatively lower than those from entire hydrolysis. However, the pure water flux was significantly higher. To verify the influences of single-side hydrolysis on subsequent modification, the PEI/PAA pair was alternatively deposited on the hydrolyzed PAN membranes to form polyelectrolyte multilayer composite membrane based on the electrostatic adsorption. The pervaporation performances of PAN-based membrane were discussed. As shown in Table 2, it was noted that, in the case of pervaporation separation of $95 \mathrm{wt} \%$ ethanol-water mixture, the permeate flux obtained from single-side hydrolyzed PAN-based composite membrane was highly improved while the selectivity was comparative with those obtained from entirely hydrolyzed PAN-based composite membrane. For example, the pervaporation flux of polyelectrolyte membrane could increase from improved from $135.6 \mathrm{~g} / \mathrm{m}^{2} \mathrm{~h}$ to $285.8 \mathrm{~g} / \mathrm{m}^{2} \mathrm{~h}$ when the water content in permeate was kept around $97.5 \%$. Obviously, the selectivity was mainly decided by the selective layer on the inner surface. However, the pore hydrolysis might decrease the pore size and increase the

Table 3

Pervaporation performance of hollow fiber PEMMs for different alcohol/water feed mixture.

\begin{tabular}{|c|c|c|c|c|c|c|}
\hline \multirow[t]{2}{*}{ Feed mixture } & \multicolumn{3}{|c|}{$\begin{array}{l}\text { Pervaporation performance of entirely } \\
\text { hydrolyzed PAN-based PEMMs }\end{array}$} & \multicolumn{3}{|c|}{$\begin{array}{l}\text { Pervaporation performance of single-side } \\
\text { hydrolyzed PAN-based PEMMs }\end{array}$} \\
\hline & $\begin{array}{l}\text { Water content in } \\
\text { permeate (wt\%) }\end{array}$ & Separation factor $(\alpha)$ & Total flux $\left(\mathrm{g} / \mathrm{m}^{2} \mathrm{~h}\right)$ & $\begin{array}{l}\text { Water content in } \\
\text { permeate (wt\%) }\end{array}$ & $\begin{array}{l}\text { Separation } \\
\text { factor }(\alpha)\end{array}$ & $\begin{array}{l}\text { Total flux } \\
\left(\mathrm{g} / \mathrm{m}^{2} \mathrm{~h}\right)\end{array}$ \\
\hline 95 wt\% ethanol-water & 97.5 & 741 & 135.6 & 97.6 & 773 & 285.8 \\
\hline 95 wt\% 2-propanol-Water & 98.8 & 1564 & 240.8 & 98.8 & 1564 & 490.0 \\
\hline 95 wt\% t-butanol-Water & 99.4 & 3148 & 320.5 & 99.5 & 3781 & 645.0 \\
\hline
\end{tabular}

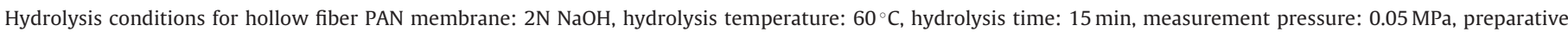

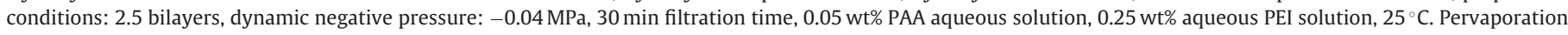
conditions: feed temperature $50^{\circ} \mathrm{C}$, down-stream pressure $100 \mathrm{~Pa}$. 
transport resistance, which in turn negatively affect the permeate flux. To further confirm the advantages of transport properties using this new method, the separation performances of different alcohol/water mixtures with the alcohols being t-butanol, and 2propanol or ethanol are compared. Table 3 suggested that in all cases the flux obtained from the single-side hydrolyzed PAN-based membrane was always higher than those from entirely hydrolyzed one. Meanwhile, the selectivity was very close for each case. Therefore, single-side hydrolysis would provide an efficient approach for the improvement of PAN-based membrane transport properties. The change of the tensile strengths and elastic modulus was also determined during the assembly process. It was noted that the mechanical strength decreased after hydrolysis compared to the virgin membrane. However, the tensile strengths and elastic modulus obtained from single-side hydrolysis were higher than those from entire hydrolysis. For example, the tensile strengths were $2.36 \mathrm{MPa}$ and $2.68 \mathrm{MPa}$ in the cases of entire and interfacial single-side hydrolysis, respectively. At the same time, it was also observed that the tensile strength increased from 2.68 MPa to $2.97 \mathrm{MPa}$ due to the deposition of polyelectrolyte pairs. Therefore, single-side hydrolysis was beneficial for maintaining a relatively high mechanical strength due to the absence of pore hydrolysis.

\section{Conclusions}

In this paper, a single-side hydrolysis was successfully accomplished by taking the interfacial hydrolysis reaction on the inner surface of solvent-impregnated hollow fiber PAN membrane. Interfacial hydrolysis reaction on cyclohexane/water phase interface was taken place by feeding alkaline aqueous solution into lumen side of cyclohexane-impregnated hollow fibers. The ATR-FTIR and EDX analyses confirmed the hydrolysis did not occur in the membrane pores. The relative looser and rougher surface was observed by using SEM and AFM in single-side hydrolysis case. Hollow fiber PEMMs were also prepared based on the single-side and entirely hydrolyzed PAN membranes. It was noted that, in the case of pervaporation separation of $95 \mathrm{wt} \%$ ethanol-water mixture, the flux was highly improved while the selectivity were still kept at a relatively high level by using single-side hydrolyzed PAN substrate membrane. Furthermore, the mechanical strength was also highly improved by using interfacial hydrolysis technique as membrane pores were protecting from alkaline hydrolysis. As PAN-based membrane plays an important role in the many processes such as pervaporation, bioproduct purification and water treatment, it was expected that the new hydrolysis technique could also potentially be used to prepare other types of PAN-based membranes.

\section{Acknowledgements}

This work was supported by the National Natural Science Foundation of China (nos. 20806001 and 20876003), the Natural Science
Foundation of Beijing (no. 8071001), the National Basic Research Program of China (no. 2009CB623404), the Beijing NOVA Programme (no. 2006B13), Beijing Municipal Science and Technology Planning Project (no. Z08000603170801), and Funding Project for Academic Human Resources Development in Institutions of Higher Learning Under the Jurisdiction of Beijing Municipality (no. PRH 200907105 and PHR201008018).

\section{References}

[1] Z.G. Wang, L.S. Wan, Z.K. Xu, Surface engineering of polyacrylonitrile-based asymmetric membranes towards biomedical applications: an overview, J. Membr. Sci. 304 (2007) 8-23.

[2] Z.W. Dai, L.S. Wan, Z.K. Xu, Surface glycosylation of polyacrylonitrile ultrafiltration membrane to improve its anti-fouling performance, J. Membr. Sci. 325 (2008) 479-485

[3] A. Toutianoush, B. Tieke, Pervaporation separation of alcohol/water mixtures using self-assembled polyelectrolyte multilayer membranes of high charge density, Mater. Sci. Eng. C 22 (2002) 459-463.

[4] Z.P. Zhao, J.D. Li, D. Wang, C.X. Chen, Nanofiltration membrane prepared from polyacrylonitrile ultrafiltration membrane by low-temperature plasma: 4. Grafting of N-vinylpyrrolidone in aqueous solution, Desalination 184 (2005) 37-44.

[5] Z.P.Zhao, J.D. Li, D.X.Zhang, C.X. Chen, Nanofiltration membrane prepared from polyacrylonitrile ultrafiltration membrane by low-temperature, plasma. I. Graft of acrylic acid in gas, J. Membr. Sci. 232 (2004) 1-8.

[6] J. Chen, J. Li, Z.P. Zhao, D. Wang, C.X. Chen, Nanofiltration membrane prepared from polyacrylonitrile ultrafiltration membrane by low-temperature plasma. 5. Grafting of styrene in vapor phase and its application, Surf. Coat. Technol. 201 (2007) 6789-6792.

[7] M. Ulbricht, A. Oechel, C. Lehmann, G. Tomaschewski, H.G. Hicke, Gas-phase photoinduced graft polymerization of acrylic acid onto polyacrylonitrile ultrafiltration membranes, J. Appl. Polym. Sci. 55 (1995) 1707-1723.

[8] J. Wang, Z. Yue, J.S. Ince, J. Economy, Preparation of nanofiltration membranes from polyacrylonitrile ultrafiltration membranes, J. Membr. Sci. 286 (2006) 333-341.

[9] X.P. Wang, N. Li, W.Z. Wang, Pervaporation properties of novel alginate composite membranes for dehydration of organic solvents, J. Membr. Sci. 193 (2001) 85-95.

[10] G. Zhang, H. Yan, S. Ji, Z. Liu, Self-assembly of polyelectrolyte multilayer pervaporation membranes by a dynamic layer-by-layer technique on a hydrolyzed polyacrylonitrile ultrafiltration membrane, J. Membr. Sci. 292 (2007) 18.

[11] G. Zhang, X. Gao, S. Ji, Z. Liu, Electric field-enhanced assembly of polyelectrolyte composite membranes, J. Membr. Sci. 307 (2008) 151-155.

[12] G. Zhang, X. Song, S. Ji, N. Wang, Z. Liu, Self-assembly of inner skin hollow fiber polyelectrolyte multilayer membranes by a dynamic negative pressure layer-by-layer technique, J. Membr. Sci. 325 (2008) 109-116.

[13] G. Zhang, N. Wang, X. Song, S. Ji, Z. Liu, Preparation of pilot-scale inner skin hollow fiber pervaporation membrane module: effects of dynamic assembly conditions, J. Membr. Sci. 338 (2009) 43-50.

[14] Z.Zhu, X. Feng, A. Penlidis, Layer-by-layer self-assembled polyelectrolyte membranes for solvent dehydration by pervaporation, Mater. Sci. Eng. C 27 (2007) 612-619.

[15] X. Qiao, Z.Zhang, Z. Ping, Hydrophilic modification of ultrafiltration membranes and their application in Salvia miltiorrhiza decoction, Sep. Purif. Technol. 56 (2007) 265-269.

[16] H.R. Lohokare, M.R. Muthu, G.P. Agarwal, U.K. Kharul, Effective arsenic removal using polyacrylonitrile-based ultrafiltration (UF) membrane, J. Membr. Sci. 320 (2008) 159-166.

[17] Z. Liu, G. Zhang, Y. Peng, S. Ji, The hollow fiber ultrafiltration membrane with inner skin and its application, Desalination 233 (2008) 55-63. 